\title{
Design of Wearable MIMO Antenna Using STUB Matching
}

\author{
${ }^{1}$ Shaik Sultan, ${ }^{2}$ Kandula Bharath, ${ }^{3}$ T V S S SAI Kishan, ${ }^{4}$ B Revanth Sai, ${ }^{5}$ K Latha \\ ${ }^{1}$ Asst. Professor, ${ }^{4}$ Student, N S Raju Institute of Technology \& India. \\ ${ }^{1}$ sksultan.ece@nsrit.edu.in, ${ }^{2}$ bharathkandula321@gmail.com, ${ }^{3}$ sai.kishan1.skk@gmail.com, \\ ${ }^{4}$ bandarurevanth3795@gmail.com, 5 konalatha99@gmail.com
}

\begin{abstract}
In this work, a Multi-band wearable microstrip patch antenna designed integrated with the defected ground structure(DGS) ${ }^{[1]}$, and the substrate being used is Denim which is flexible ${ }^{[4]}$ and can be easily fabricated on common wearable materials. This Radiating patch antenna is designed with the optimized dimensions and suits appropriately for the communication in wearable electronics as well as in smart textile application. The designed antenna operates at resonating frequencies of $4.885 \mathrm{GHz}$ and $5.57 \mathrm{GHz}$. Further the design is modified to a 2-element MIMO ${ }^{[2]}$ antenna using T-shaped Stub matching technique to reduce mutual coupling and resonate at frequency of $8 \mathrm{GHz}$ by designing and simulating in CST Microwave Studio 2019 software and the enhanced results like Directivity, Gain, E-field are obtained.
\end{abstract}

Keywords: Wearable Antenna, Microstrip Patch, DGS, MIMO, Textile Antenna, T-Stub, CST Microwave Studio

\section{INTRODUCTION}

Now a days rapid development of wearable antennas ${ }^{[5]}$ to reduce the society's medical expenses by remote telemetry, bringing them to more safe, efficient, faster rescue operations in real-life monitoring and observation of athletic performance parameters are just a few applications that illustrate the capacity and potential of smart advanced wearable technological systems. For a wearable antenna ${ }^{[6],[8]}$ the parameters which anticipate mechanical influences such as bending, crumpling and also compression.

Wearable Antennas are essentially any antenna that is specifically designed to function while being worn ${ }^{[3]}$. Wearable antennas are becoming increasingly common in consumer electronics. Some of the applications of wearable antennas include health monitoring, physical training, navigation ${ }^{[9]}$, medicine, military, etc. And mainly the challenging task is to maintain acceptable radiation characteristics with a low-level of Specific Absorption Rate (SAR).

MIMO stands for Multiple Input Multiple Outputs. MIMO technique is implemented in antennae to improve communication vastly which consists of multiple radiating elements for transmission and reception. Stub matching is used for isolation between these multiple radiating elements.

\section{PROPOSED ANTENNA DESIGN}

A. Single Antenna Element Design and Simulation

For the design of the proposed antenna, microstrip patch antenna is used which consists of three layers which are ground, dielectric substrate and radiating patch. The threedimensional view of the antenna is illustrated in figure 1.

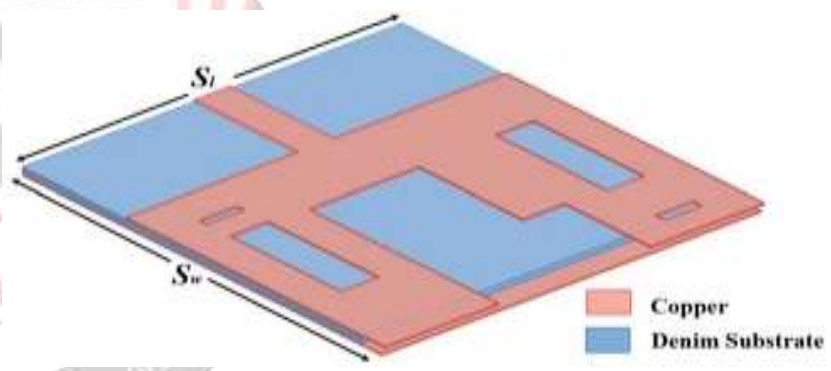

Figure 1. three-dimensional structure of the antenna.

As shown in the figure 1, A microstrip wearable antenna designed with dielectric substrate Denim having Relative Permittivity of 1.6 with thickness of $1.6 \mathrm{~mm}$.

In general, the Di-electric substrate is placed between the Ground and the radiator patch. The material which is used for Ground and the radiator patch is the annealed copper.

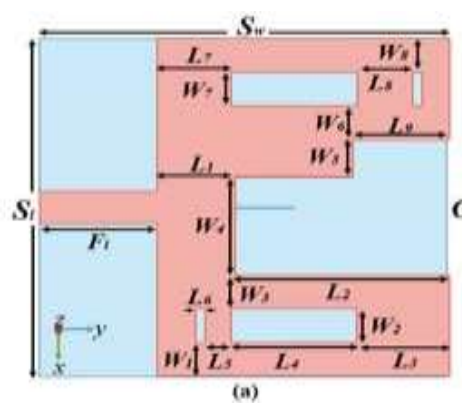

Figure 2(a) Top View

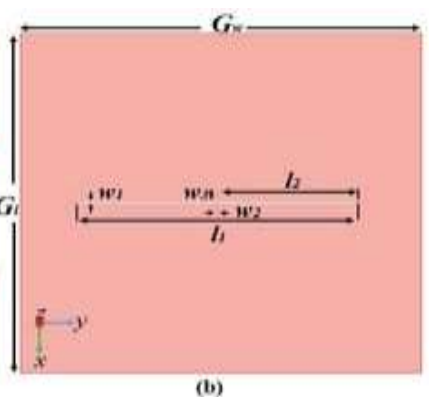

Figure 2(b) Bottom View (Ground)

All the geometrical dimensions of designed antenna are shown in Figure 2. 
The Top and Bottom views of the designed antenna are shown in Figure 2(a) and Figure 2(b) respectively.

The proposed antenna with enhanced designed parameters is as follows:

Designed parameters for Section 1: $S_{w}=104.778 \mathrm{~mm}, S_{l}=$ $100 \mathrm{~mm}, W_{l}=10 \mathrm{~mm}, W_{2}=10 \mathrm{~mm}, W_{3}=9.9 \mathrm{~mm}$, $W_{4}=29.047 \mathrm{~mm}, W_{5}=11.0526 \mathrm{~mm}, W_{6}=10.22 \mathrm{~mm}, W_{7}=10$ $\mathrm{mm}, W_{8}=10 \mathrm{~mm}, f_{L}=30 \mathrm{~mm}, L_{l}=20 \mathrm{~mm}, L_{2}=54.778$ $\mathrm{mm}, L_{3}=23.982 \mathrm{~mm}, L_{4}=32.117 \mathrm{~mm}, L_{5}=6.7447 \mathrm{~mm}$, $L_{6}=2.25 \mathrm{~mm}, L_{7}=19.117 \mathrm{~mm}, L_{8}=14.0439 \mathrm{~mm}, L_{9}=2.51$ $\mathrm{mm}, G_{w}=104 \mathrm{~mm}, G_{l}=100 \mathrm{~mm}, l_{l}=30 \mathrm{~mm}, l_{2}=14.95$ $\mathrm{mm}, w_{1}=0.2 \mathrm{~mm}, w_{2}=0.1 \mathrm{~mm}, w_{3}=1.25 \mathrm{~mm}$ ).

The antenna design is obtained by optimizing a number of stages. A rectangular patch with dimensions of $74.778 \mathrm{x}$ $100 \mathrm{~mm} 2$. The dimensions of the denim substrate, Ground plane, and the top conducting patch are different. The antenna operates at distant frequencies of 2-7 GHz. Here the slots are patched which is considered.

A plus sign in Figure 2(b) shows the plus (+) shaped slot in the ground is introduced. As it states that the introduction of the defected ground concept in the antenna design.

\section{SIMULATED RESULTS}

\section{A. Return Loss:}

The above antenna design shown Figure 1 is simulated using CST Microwave Studio 2019 and its respective return loss responses to the frequency is shown in Figure 3.

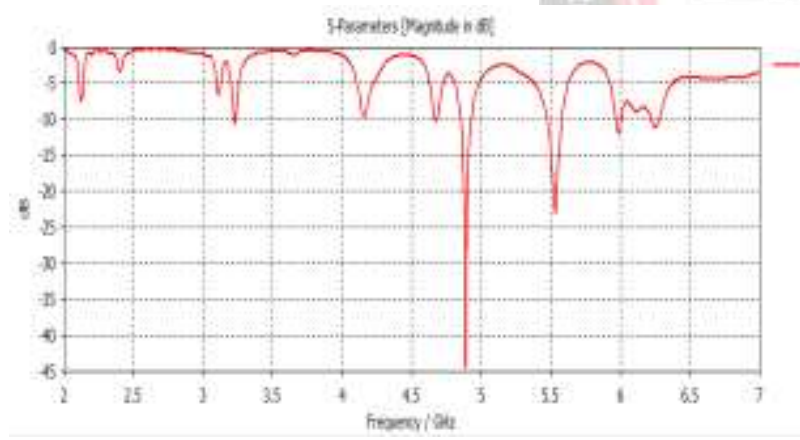

Figure 3: Return Loss S11 (S-Parameter)

$\mathrm{S}$-parameter describes the response of an N-port which means input to output relation between ports. The $S(11)$ is called the return loss. When the $S$ parameter $S(11)$ is $0 \mathrm{~dB}$ then all power is reflected. If the $S$ parameter $S(11)$ is -10 $\mathrm{dB}$ then $3 \mathrm{~dB}$ of total power is transferred to the antenna with the loss of $-7 \mathrm{~dB}$ as reflected power. Therefore, $\mathrm{S}$ parameter $S$ (11) should be less than $-10 \mathrm{~dB}$ so as for the antenna to perform very effectively.

The designed antenna has a return loss of $-45.162 \mathrm{~dB}$, , 23.067 dB for, $4.885 \mathrm{GHz}, 5.57 \mathrm{GHz}$.

From the simulated S11 plot, the frequency and the return loss were observed. Minimum return loss attained is observed at

- Frequency $(\mathrm{fr})=4.885 \mathrm{GHz} \mathrm{S} 11(\mathrm{~dB})=-45.162$

- Frequency $(\mathrm{fr})=5.57 \mathrm{GHz} \quad \mathrm{S} 11(\mathrm{~dB})=-23.067$
The performance characteristics Directivity, Gain, Realized Gain of the single element antenna is simulated at the following frequencies of $4.885 \mathrm{GHz}$ and $5.57 \mathrm{GHz}$, respectively. Radiation Pattern are shown accordingly with their respective performance characteristics.

B. Directivity:
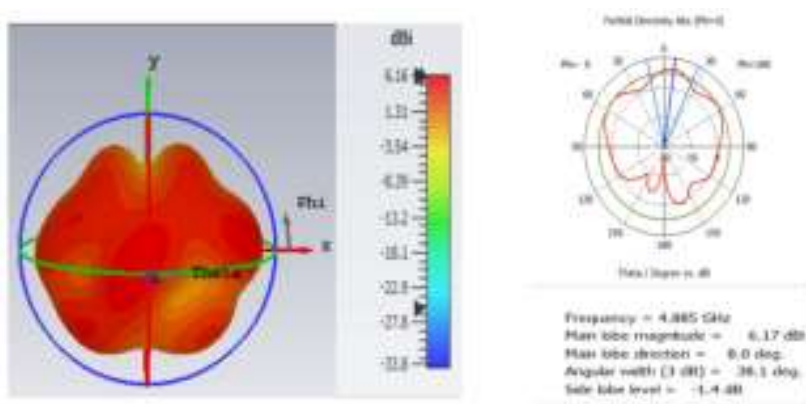

Fig.4a: Directivity 3D Plot \& Polar Plot of frequency 4.885 GHz.
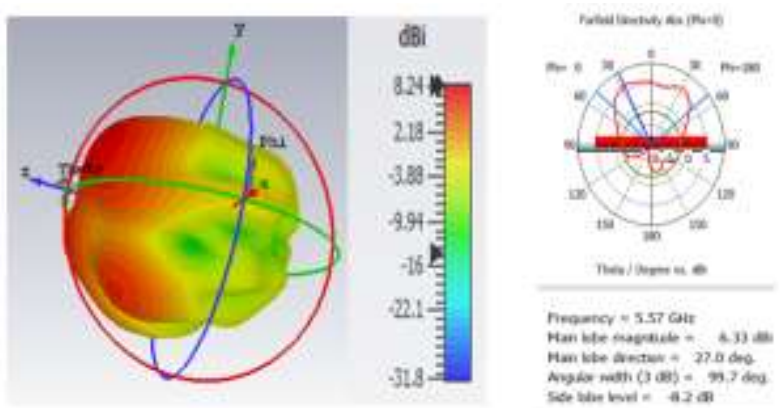

Fig.4b: Directivity 3D Plot of \& Polar Plot of frequency $5.57 \mathrm{GHz}$.

The Directivity obtained is $6.17 \mathrm{dBi}$ and $8.24 \mathrm{dBi}$ at 4.885 $\mathrm{GHz}$ is and at $5.57 \mathrm{GHz}$ respectively as shown in figures $4 \mathrm{a}$ and $4 \mathrm{~b}$.

C. Gain:
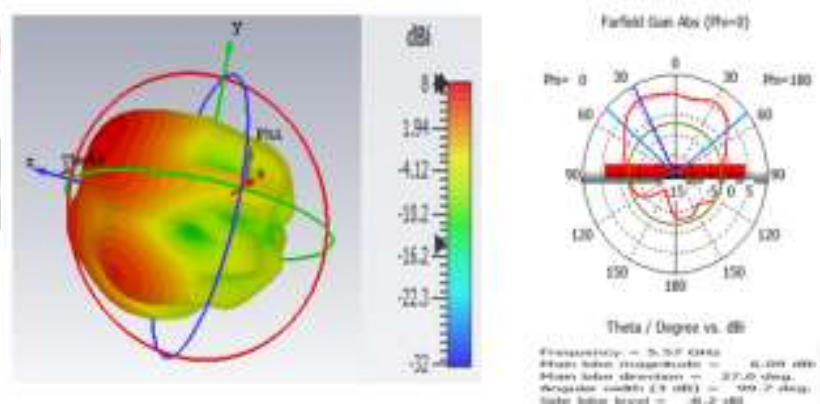

Fig.4c: Gain 3D Plot \& Polar Plot of frequency $4.885 \mathrm{GHz}$.
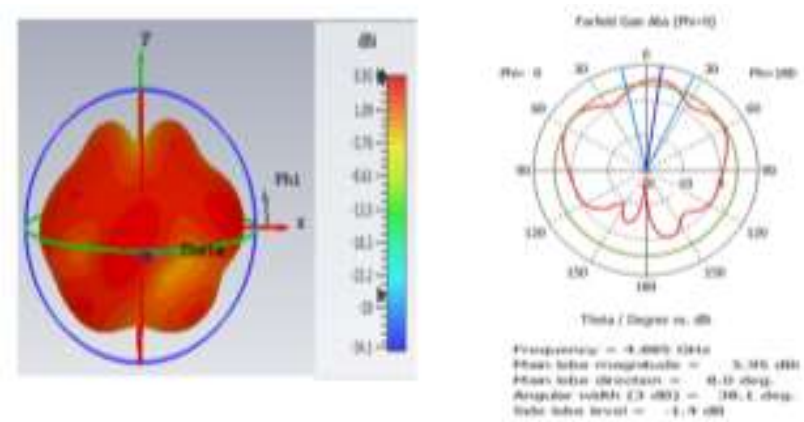

Fig.4d: Gain 3D Plot of \& Polar Plot of frequency 5.57 GHz.

The Gain obtained is $5.95 \mathrm{dBi}$ and $8 \mathrm{dBi}$ at $4.885 \mathrm{GHz}$ is and at $5.57 \mathrm{GHz}$ respectively as shown in figures $4 \mathrm{c}$ and 4d. 
D: Realized Gain:

The Realized Gain obtained is $5.95 \mathrm{dBi}$ and $7.68 \mathrm{dBi}$ at $4.885 \mathrm{GHz}$ is and at $5.57 \mathrm{GHz}$ respectively as shown in figures $4 \mathrm{e}$ and $4 \mathrm{f}$.
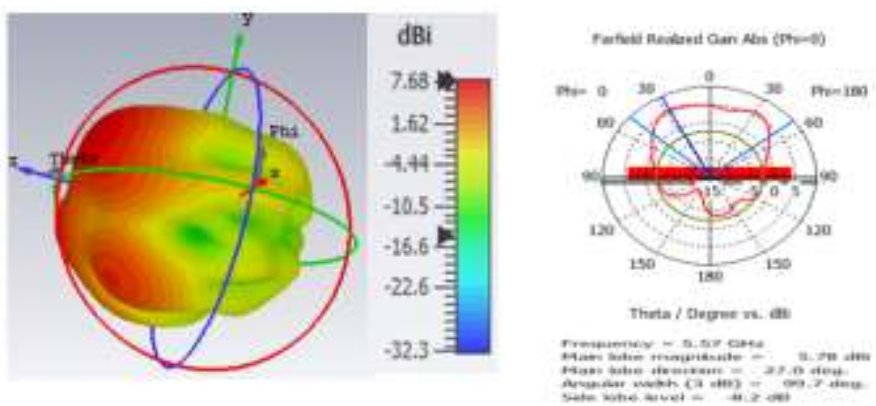

Fig.4e: Realized Gain 3D Plot \& Polar Plot of frequency 4.885 GHz.
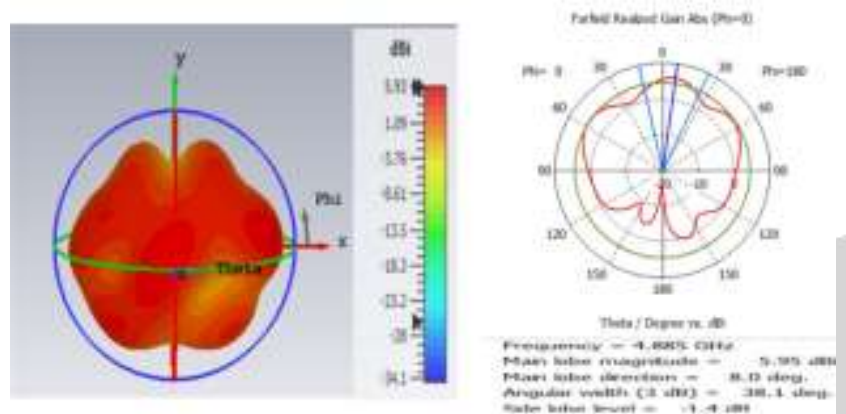

Fig.4f: Realized Gain 3D Plot of \& Polar Plot of frequency 5.57 GHz. E. E-Field Pattern:
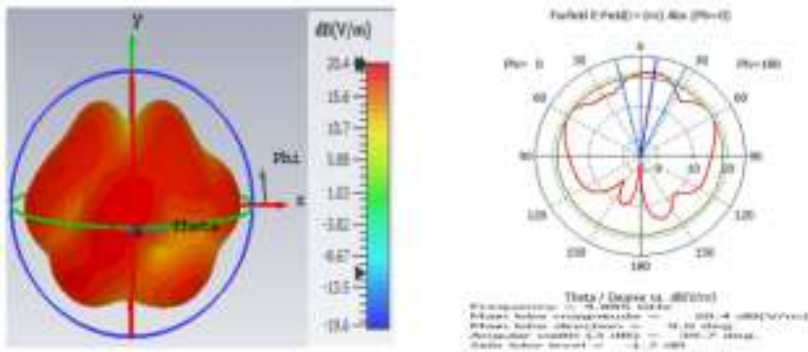

Fig.4g: E-field 3D Plot \& Polar Plot of frequency $4.885 \mathrm{GHz}$.
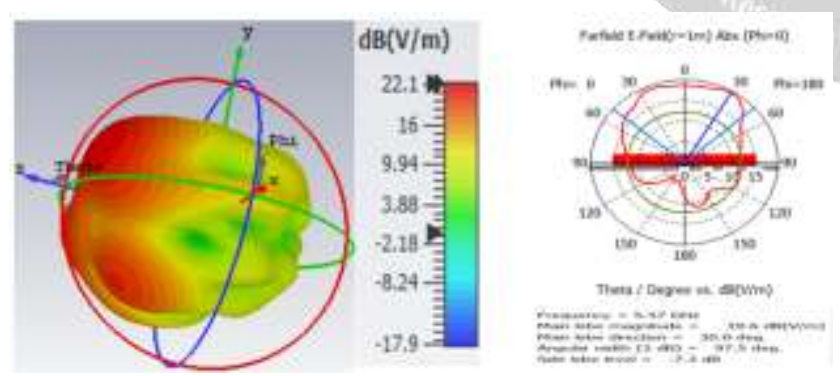

Fig.4h: E-field 3D Plot of \& Polar Plot of frequency 5.57 GHz.

The E-Field Patern obtained is $20.4 \mathrm{~V} / \mathrm{m}$ and $22.1 \mathrm{~V} / \mathrm{m}$ at 4.885 GHz is and at $5.57 \mathrm{GHz}$ respectively as shown in figures $4 \mathrm{~g}$ and $4 \mathrm{~h}$.

\section{DESIGN OF TWO ELEMENT MIMO CONFIGURATION}

The single element wearable antenna proposed is used in a two-element wearable MIMO configuration and the design of the two-element wearable MIMO antenna configuration is initiated by providing isolation by providing appropriate spacing between the antenna elements. The prototype of the proposed two-element wearable MIMO antenna with
Top and Bottom views are shown in figures Fig5(a), Fig5(b) respectively.

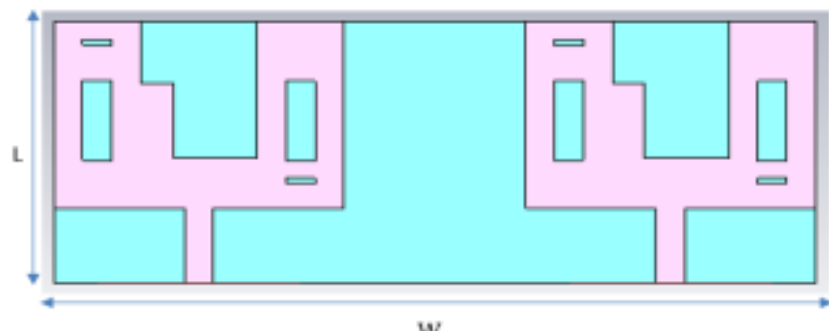

$\mathrm{W}_{5}$

Figure 5(a) Top View (Patch)

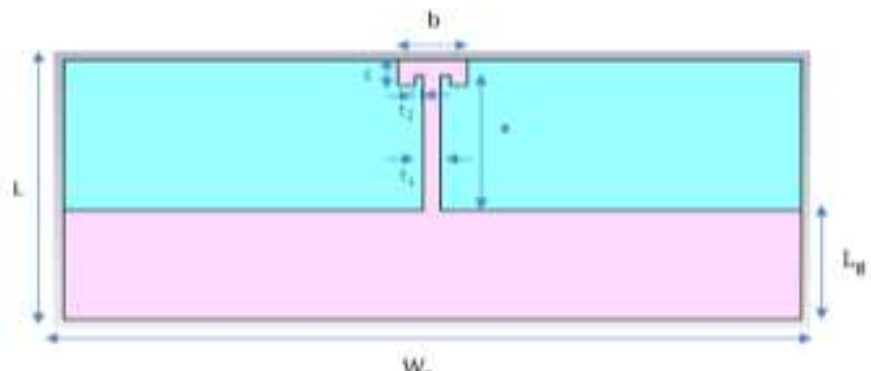

Figure 5(b) BottomView (Ground)

In this section, the structure of the proposed wearable MIMO antenna with the T-Shaped stub in the ground plane is represented in the Fig5(b). The wearable MIMO antenna dimensions are represented as follows: $\mathrm{L}=30$ $\mathrm{mm}, L_{g}=12.5 \mathrm{~mm}, W_{s}=42 \mathrm{~mm}, \mathrm{a}=16.5 \mathrm{~mm}, \mathrm{~b}=4 \mathrm{~mm}$, $\mathrm{c}=3 \mathrm{~mm}, t_{1}=1 \mathrm{~mm}, t_{2}=0.5 \mathrm{~mm}$.

\section{SIMULATED RESULTS}

The following Return loss of the proposed MIMO configuration represented by $\left|S_{11}\right|,\left|S_{12}\right|,\left|S_{21}\right|,\left|S_{22}\right|$ parameters are illustrated in the following figures Fig 6a, Fig $6 \mathrm{~b}$, Fig $6 \mathrm{c}$ respectively.

\section{A. S-Parameters:}

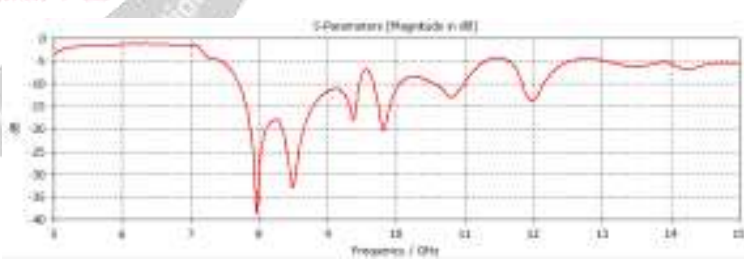

Figure 6a: Return Loss S11Figure 6b: Return Loss S22

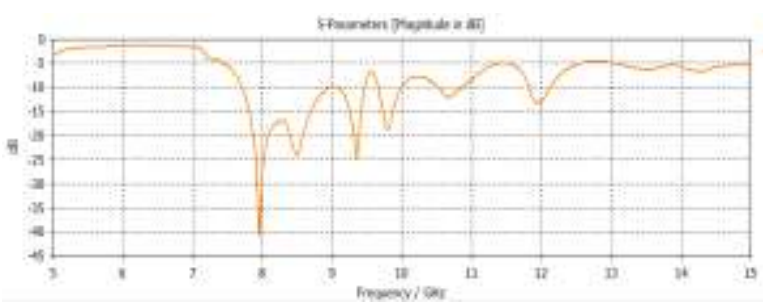

Figure 6b: Return Loss S22

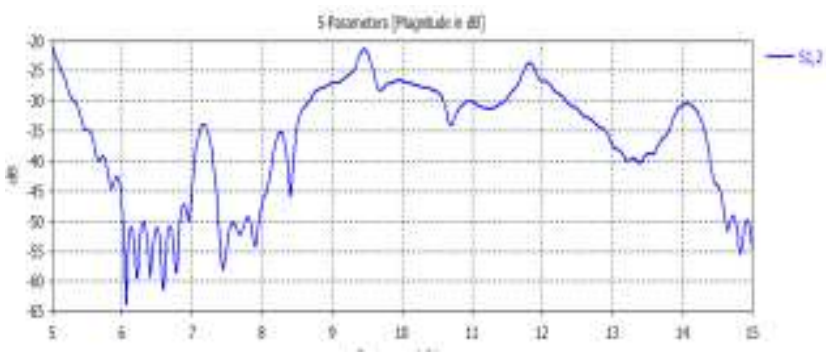

Figure 6c: Return Loss S12 (S-Parameter) 
From the simulated S11, S22, S12, S21 plots the frequency and the return loss, mutual coupling were observed. Minimum return loss attained is observed at

- Frequency (fr $)=8 \mathrm{GHz} \quad \mathrm{S} 11(\mathrm{~dB})=-39.20 \mathrm{~dB}$

- Frequency $(\mathrm{fr})=8 \mathrm{GHz} \quad \mathrm{S} 22(\mathrm{~dB})=-41.90 \mathrm{~dB}$

- Frequency $(\mathrm{fr})=8 \mathrm{GHz} \quad \mathrm{S} 12=\mathrm{S} 21(\mathrm{~dB})=$ $54.5 \mathrm{~dB}$

Radiation Parameters such as the Directivity, Realised Gain, E-Field, Gain of the Antenna [1] and Antenna [2] are represented with respective 3D Plots and 2D Polar Plots. Both the antennas, the Antenna [1] and Antenna [2] are designed to operate at the frequency of $8 \mathrm{GHz}$.

B. Directivity:
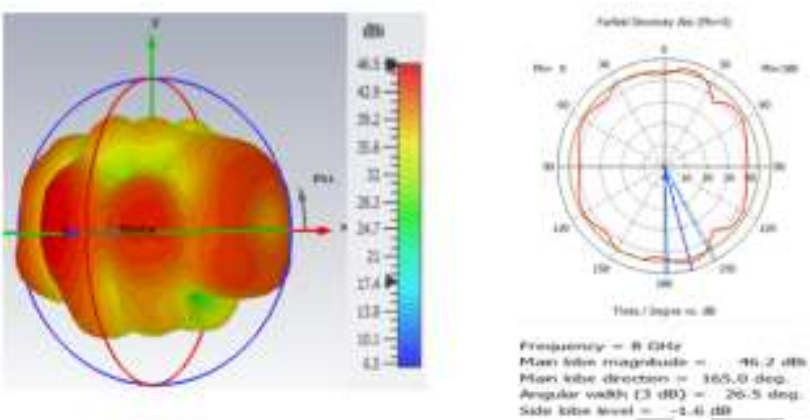

Fig.6d: Directivity 3D Plot \& Polar Plot of Antenna1 at frequency 8 GHz.
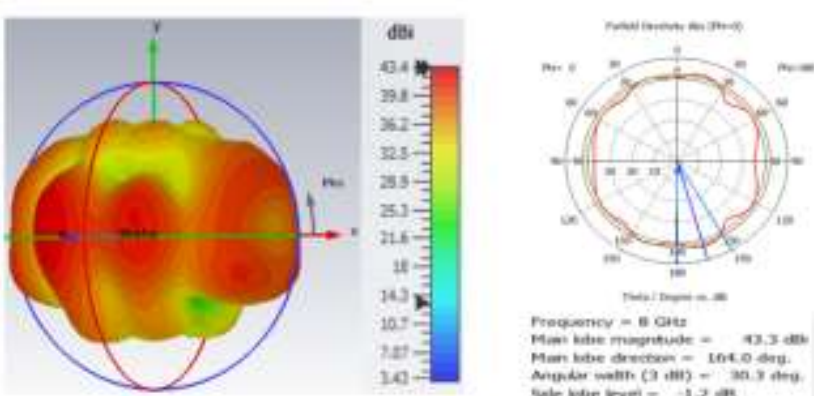

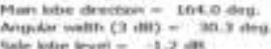

Fig.6e: Directivity 3D Plot \& Polar Plot of Antenna2 at frequency 8 GHz.

The Directivity obtained is $46.5 \mathrm{~dB}$ and $43.4 \mathrm{~dB}$ at $8 \mathrm{GHz}$ of Antenna 1 and Antenna2 respectively as shown in figures $6 \mathrm{~d}$ and $6 \mathrm{e}$.

\section{Gain:}
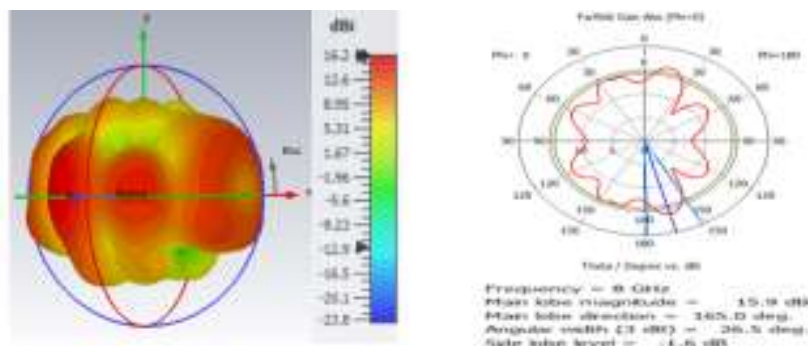

Fig.6f: Gain 3D Plot \& Polar Plot of Antenna1 at frequency $8 \mathrm{GHz}$.
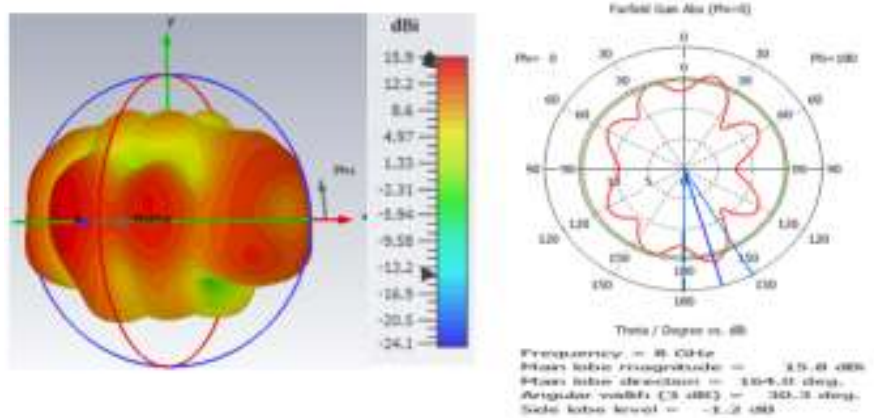

Fig.6g: Gain 3D Plot \& Polar Plot of Antenna2 at frequency $8 \mathrm{GHz}$.

The Gain obtained is $16.2 \mathrm{dBi}$ and $15.9 \mathrm{~dB}$ at $8 \mathrm{GHz}$ of Antenna 1 and Antenna2 respectively as shown in figures $6 \mathrm{f}$ and $6 \mathrm{~g}$.

\section{D: Realized Gain:}
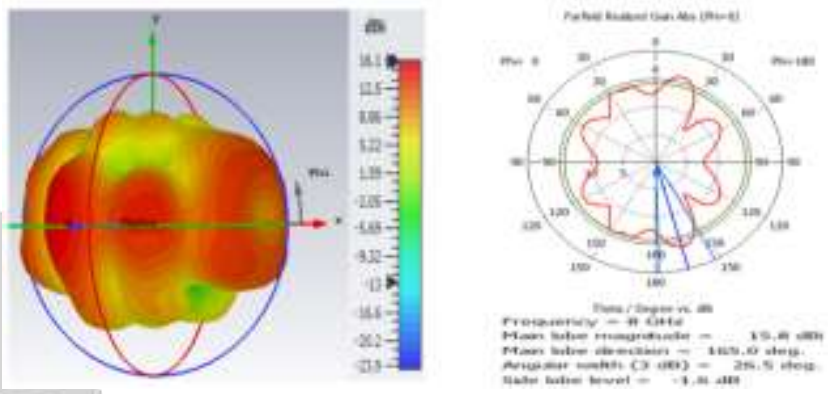

Fig.6h: Realized Gain 3D Plot \& Polar Plot of Antenna1 at frequency 8 GHz.
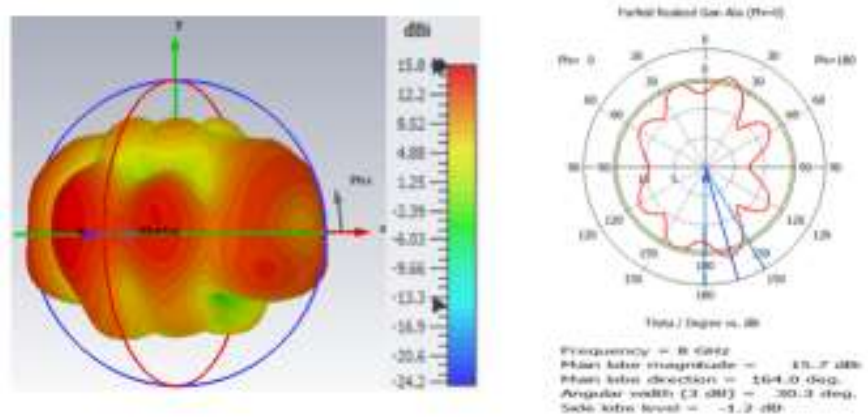

Fig.6i: Realized Gain 3D Plot \& Polar Plot of Antenna2 at frequency $8 \mathrm{GHz}$

The Realized Gain obtained is $16.1 \mathrm{dBi}$ and $15.8 \mathrm{dBi}$ at $8 \mathrm{GHz}$ of Antenna 1 and Antenna2 respectively as shown in figures $6 \mathrm{~h}$ and $6 \mathrm{i}$.

\section{E. E-Field Pattern:}
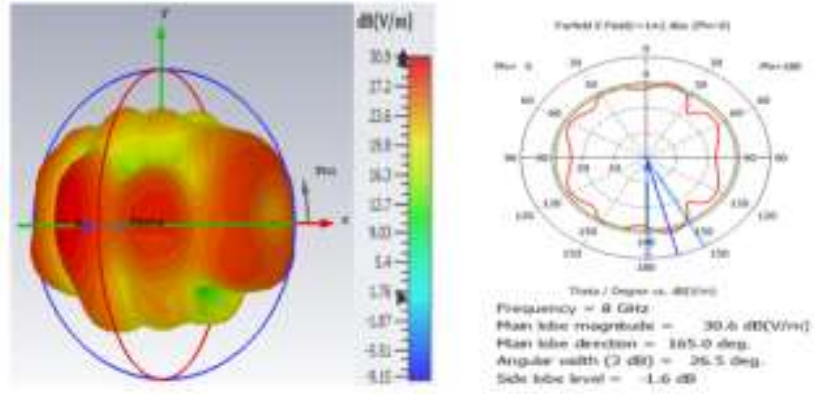

Fig.6j: E-Field 3D Plot \& Polar Plot of Antenna1 at frequency 8 GHz.

The E-Field Pattern obtained is $30.9 \mathrm{~V} / \mathrm{m}$ and $30.5 \mathrm{~V} / \mathrm{m}$ at $8 \mathrm{GHz}$ of Antenna 1 and Antenna2 respectively as shown in figures $6 \mathrm{j}$ and $6 \mathrm{k}$. 


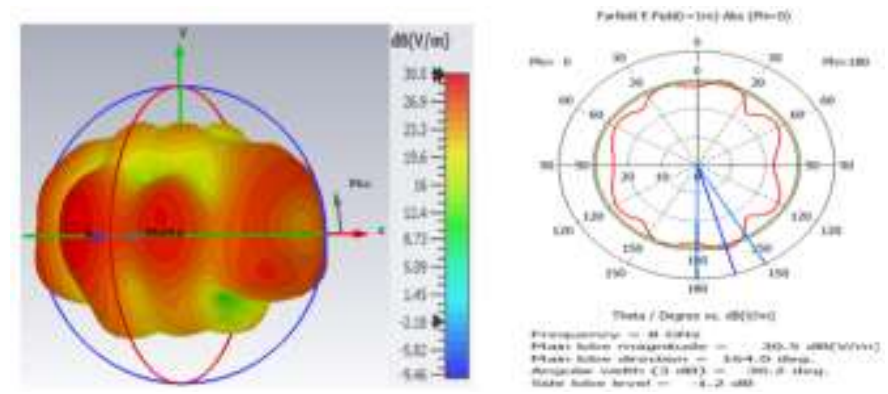

Fig.6k: E-Field 3D Plot \& Polar Plot of Antenna2 at frequency 8 GHz.

VII. SIMULATED RESULTS OF SINGLE ELEMENT AND 2-ELEMENTS MIMO ANTENNA:

\begin{tabular}{|c|c|c|c|c|c|c|}
\hline TYPE & $\begin{array}{c}\text { FREQUEN } \\
\text { CY }\end{array}$ & S11 & $\begin{array}{c}\text { DIRECTIVI } \\
\text { TY }\end{array}$ & $\begin{array}{c}\text { GAI } \\
\mathrm{N}\end{array}$ & $\begin{array}{l}\text { REALIZE } \\
\text { D GAIN }\end{array}$ & $\begin{array}{c}\text { E- } \\
\text { FIEL } \\
\text { D }\end{array}$ \\
\hline \multirow{2}{*}{$\begin{array}{c}\text { Single } \\
\text { eleme } \\
\text { nt }\end{array}$} & $\begin{array}{c}\mathrm{F}=4.885 \\
\mathrm{GHz}\end{array}$ & $\begin{array}{c}- \\
45.16 \\
2 \mathrm{~dB}\end{array}$ & $6.17 \mathrm{dBi}$ & $\begin{array}{l}5.95 \\
\mathrm{dBi}\end{array}$ & $5.95 \mathrm{dBi}$ & $\begin{array}{l}20.4 \\
\mathrm{~V} / \mathrm{m}\end{array}$ \\
\hline & $\begin{array}{c}\mathrm{F}=5.57 \\
\mathrm{GHz}\end{array}$ & $\begin{array}{c}- \\
23.06 \\
7 \mathrm{~dB}\end{array}$ & $8.24 \mathrm{dBi}$ & $\begin{array}{c}8 \\
\mathrm{dBi}\end{array}$ & $7.68 \mathrm{dBi}$ & $\begin{array}{l}22.1 \\
\mathrm{~V} / \mathrm{m}\end{array}$ \\
\hline \multirow{2}{*}{$\begin{array}{c}2- \\
\text { eleme } \\
\text { nt } \\
\text { MIM } \\
\text { O } \\
\text { antenn } \\
\text { a }\end{array}$} & $\begin{array}{c}\mathrm{F}=8 \mathrm{GHz} \\
{[\mathrm{S} 11]}\end{array}$ & $\begin{array}{c}-39.2 \\
\mathrm{~dB}\end{array}$ & $46.50 \mathrm{dbi}$ & $\begin{array}{c}16.2 \\
2 \\
\mathrm{dBi} \\
\end{array}$ & $16.13 \mathrm{dBi}$ & $\begin{array}{c}30.85 \\
\mathrm{~dB} \\
\mathrm{~V} / \mathrm{m}\end{array}$ \\
\hline & $\begin{array}{c}\mathrm{F}=8 \mathrm{GHz} \\
{[\mathrm{S} 22]}\end{array}$ & $\begin{array}{c}-41.9 \\
\mathrm{~dB}\end{array}$ & $43.43 \mathrm{dBi}$ & $\begin{array}{c}15.8 \\
8 \\
\mathrm{dBi}\end{array}$ & $15.79 \mathrm{dBi}$ & $\begin{array}{c}30.54 \\
\mathrm{~dB} \\
\mathrm{~V} / \mathrm{m}\end{array}$ \\
\hline
\end{tabular}

Table 1: Comparative Analysis of the Single element Antenna to the 2 Element MIMO Antenna

The table 1: gives the comparative analysis of the Single element Patch antenna with DGS in the Ground and 2element MIMO antenna designed using T-shaped stub matching technique and which provide an enhancement in the Directivity by 8 times, Gain has doubled, and E-field pattern increased by $10 \mathrm{~V} / \mathrm{m}$.

\section{CONCLUSION}

As we can see, design of wearable antennas is a significant challenge, because the body directly degrades the performance of the antenna. The best method of mitigation is to maximize the distance between the antenna and the body. This is a bit obvious, but also critical. By applying MIMO technique the single element is placed in the Same orientation considering as 2 elements and feeding individual antenna with individual strip line and isolation is done by using $\mathrm{T}$ - Shaped Stub in ground which resonates at $8 \mathrm{GHz}$ and band of operation $7.7 \mathrm{GHz}$ to $9.46 \mathrm{GHz}$ with an enhanced directivity of $46.50 \mathrm{dBi}$ and $43.43 \mathrm{dBi}$ element 1 and element 2 respectively. Further enhancement can be made by decreasing ground area with DGS Principle.

\section{REFERENCES}

[1] Roopan, Diptiranjan Samantaray and Somak Bhattacharyya, "A Multiband Wearable Antenna with Defected Ground Structure" in URSI AP-RASC 2019, New Delhi, India, 09 15 March 2019.
[2] Dinesh Yadav, Mahesh P. Abegaonkar, Shiban K. Koul,Vivekanand Tiwari, and Deepak Bhatnagar, "Two Element Band-Notched UWB MIMO Antenna with High and Uniform Isolation" in Progress In Electromagnetics Research M, Vol. 63, 119-129, 2018

[3] Sam Agneessens, Student Member, IEEE, Sam Lemey, Thomas Vervust, Hendrik Rogier, Senior Member, IEEE, "Wearable, Small, and Robust: the Circular Quarter-Mode Textile Antenna", Citation information: DOI 10.1109/LAWP.2015.2389630, IEEE Antennas and Wireless Propagation Letters.

[4] Saud M. Saeed, Student Member, IEEE, Constantine A. Balanis, Life Fellow, IEEE, Craig R. Birtcher, Ahmet C. Durgun, Member, IEEE and Hussein N. Shaman, Member, IEEE, “ Wearable Flexible Reconfigurable Antenna Integrated With Artificial Magnetic Conductor ", Citation information: DOI 10.1109/LAWP.2017.2720558, IEEE Antennas and Wireless Propagation Letters.

[5] ZhiHao Jiang, Member, IEEE, DonovanE. Brocker, StudentMember, IEEE, PeterE. Sieber, StudentMember, IEEE, and Douglas H. Werner, Fellow, IEEE, “A Compact, Low-Profile Meta surface-Enabled Antenna for Wearable Medical Body-Area Network Devices", IEEE TRANSACTIONS ON ANTENNAS AND PROPAGATION, VOL.62, NO.8, AUGUST 2014.

[6] Ivo Locher, Student Member, IEEE, Maciej Klemm, Student Member, IEEE, Tünde Kirstein, and Gerhard Tröster, Senior Member, IEEE, "Design and Characterization of Purely Textile Patch Antennas", IEEE TRANSACTIONS ON ADVANCED PACKAGING, VOL. 29, NO. 4, NOVEMBER 2006.

[7] Shaozhen Zhu, Student Member, IEEE, and Richard Langley, "Dual-Band Wearable Textile Antenna on an EBG Substrate", IEEE TRANSACTIONS ON ANTENNAS AND PROPAGATION, VOL. 57, NO. 4, APRIL 2009.

[8] K.Agarwal, Y.X.Guo, and B.Salam,"Wearable AMC backed near end fire antenna for on-body communications on latex substrate," IEEE Transaction on Components, Packaging and Manufacturing Technology, 6, 3, Mar.2016, pp. 346358, doi: 10.1109/TCPMT.2016.2521487.

[9] X.Q. Zhu, Y. X. Guo and W.Wu, "A compact dual- band antenna for wireless body-area network applications," IEEE Antennas Wireless Propagation. Lett. 15, May 2015, pp. 98 101, doi:10.1109/LAWP.2015.2431822.

[10] P. J. Soh, G. A. E. Vandenbosch, S. L. Ooi, and N.H.M.Rais, "Design of a Broadband all-Textile Slotted PIFA," IEEE Transactions on Antennas and Propagation, 60, 1, Jan. 2012, pp. 379-384, doi:10.1109/TAP.2011.2167950. 